\title{
Grain Coarsening Effects of Chromium and Iron in Au-Ag-Cu Alloys
}

\section{Ott and Ch. J. Raub}

Forschungsinstitut für Edelmetalle und Metallchemie, Schwảbisch Gmünd, West Germany

Chromium and iron in concentrations as low as 0.3-0.5 per cent have been found to cause a marked coarsening of the microstructure of 18 carat $A u-A g-C u$ alloys on annealing. Where minimum grain growth during annealing is required, as in the fabrication of rings and chains, the concentrations of these metals should therefore be kept at a low level.

In the fabrication of carat gold jewellery the extent of working or deformation of $\mathrm{Au}-\mathrm{Ag}-\mathrm{Cu}$ alloys between annealing treatments is normally monitored, since if it is less than about 30 per cent with most alloy compositions then grain growth during even relatively mild annealing treatments may be excessive and weak coarse grained structures may develop (1). These form surface patterns ('orange peel' effect) on further working, and in extreme cases the grain boundaries which delineate these patterns may deepen with disastrous effects. High carat red alloys in particular must not be annealed after they have had only small deformation.

During a systematic investigation of the effects of various metals in small concentrations on the microstructures and properties of 18 carat red and yellow gold alloys we have discovered that exceptionally large grained structures also develop in $\mathrm{Au}-\mathrm{Ag}-\mathrm{Cu}$ alloys in the presence of iron or chromium even though the degree of deformation before annealing is as high as 70 per cent. The effect is especially pronounced in silver-containing yellow gold alloys.

The effects of concentrations of up to 0.5 per cent iron or chromium were studied. The experimental conditions were those outlined in the

\section{Table}

Experimental Conditions

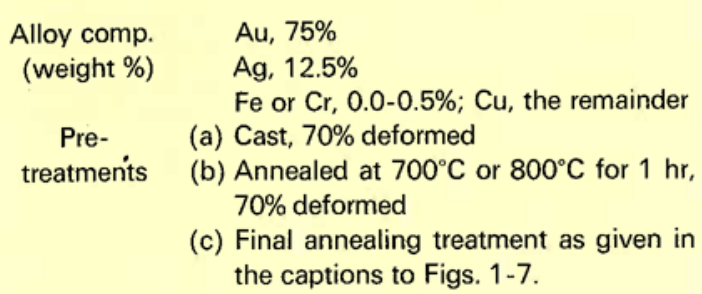

(c) Final annealing treatment as given in the captions to Figs. 1-7.

Table, and the microstructures observed are illustrated in Figures 1-7.

With a final annealing treatment at $700^{\circ} \mathrm{C}$ for 1 hour, iron and chromium concentrations of as little as 0.3 per cent already had a significant effect on grain size. If these concentrations were increased to about 0.5 per cent very coarse grains were observed. Figures 1-3 illustrate the latter effects.

If the final anrealing treatment was at $800^{\circ} \mathrm{C}$ for 1 hour, as may often happen in practice, the deleterious effects of chromium and iron additions showed up (see Figures 4-6) even more clearly. Whereas 0.3 per cent iron or chromium increased the grain size by a factor of about 2 , higher concentrations caused extreme grain growth (Figure 7).

No theoretical explanation of these effects can be given at this stage. It will be apparent, however, that they are important for gold jewellery manufacturers. Iron in particular is an element which can easily be introduced into alloys by remelting scrap or by bad refining. If alloys contaminated in this way are annealed during fabrication under the conditions found effective for uncontaminated alloys, coarse grained structures are likely to develop and give rise to production difficulties.

To ensure reproducibility of the properties of alloys used in production, especially of such articles as rings and chains in which a coarse structure is a disadvantage, it is therefore advisable that the iron and chromium concentrations in the alloys should be kept at a low level, and preferably below 0.1 per cent.

\section{Acknowledgements}

We wish to thank the Chamber of Mines of South Africa and the International Gold Corporation for supporting the research program during the course of which the above effects were observed.

Reference

1 O. Loebich, Z. Metallk., 1953, 44, 288-292 


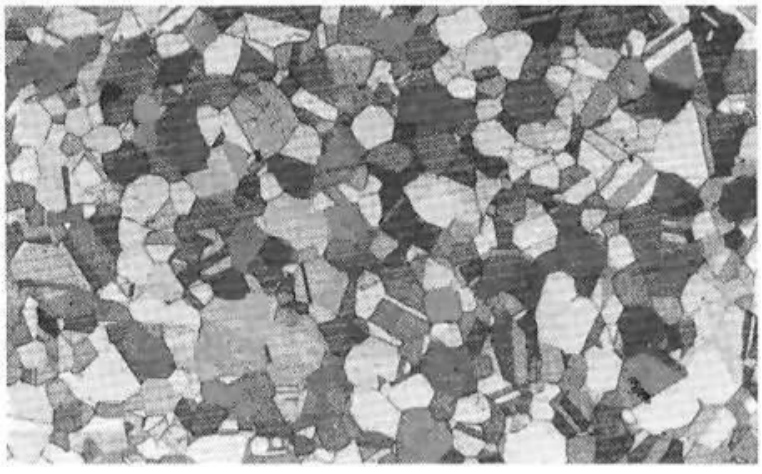

Fig. 118 carat yellow gold, annealed 1 hour, $700^{\circ} \mathrm{C}, \times 100$

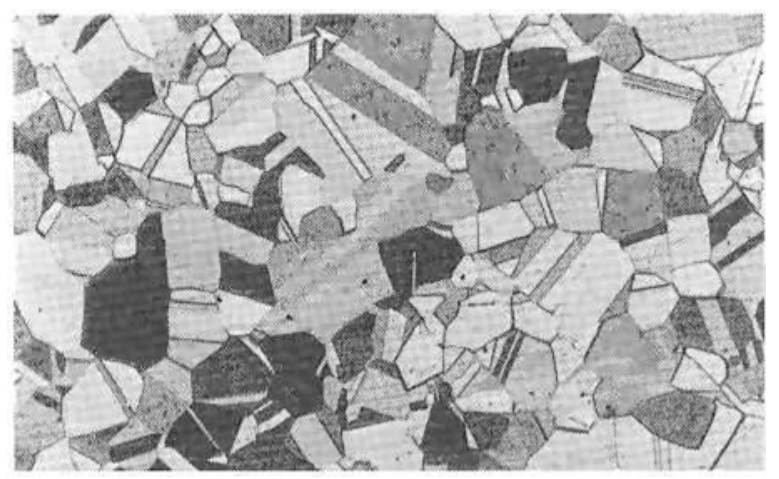

Fig. 318 carat yellow gold $+0.5 \% \mathrm{Cr}$, annealed 1 hour, $700^{\circ} \mathrm{C}, \times 100$

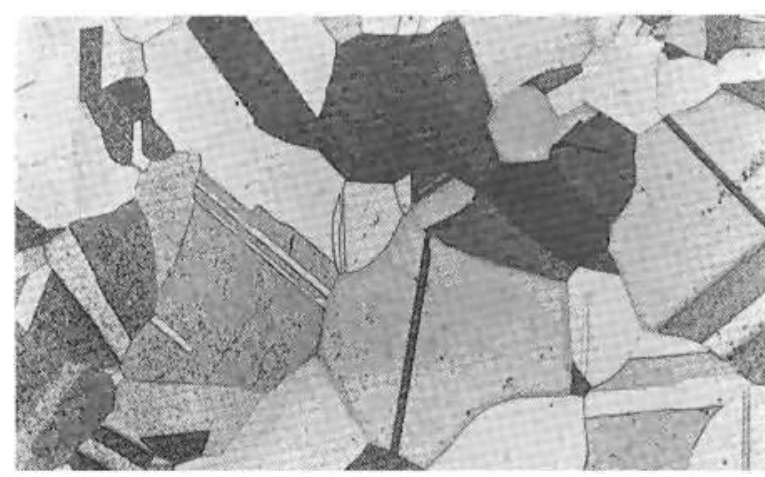

Fig. 518 carat yellow gold $+0.3 \% \mathrm{Fe}$, annealed 1 hour, $800^{\circ} \mathrm{C}, \times 100$

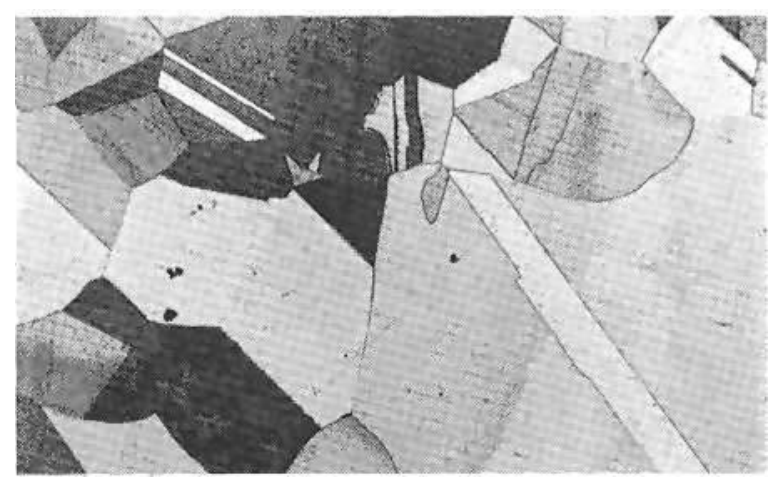

Fig. 718 carat yellow gold $+0.5 \% \mathrm{Fe}$, annealed 1 hour, $800^{\circ} \mathrm{C}, \times 100$

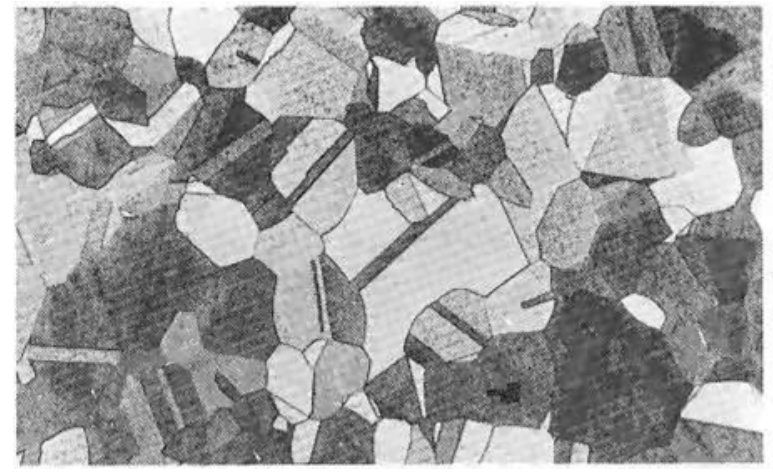

Fig. 218 carat yellow gold $+0.5 \% \mathrm{Fe}$, annealed 1 hour, $700^{\circ} \mathrm{C}, \times 100$

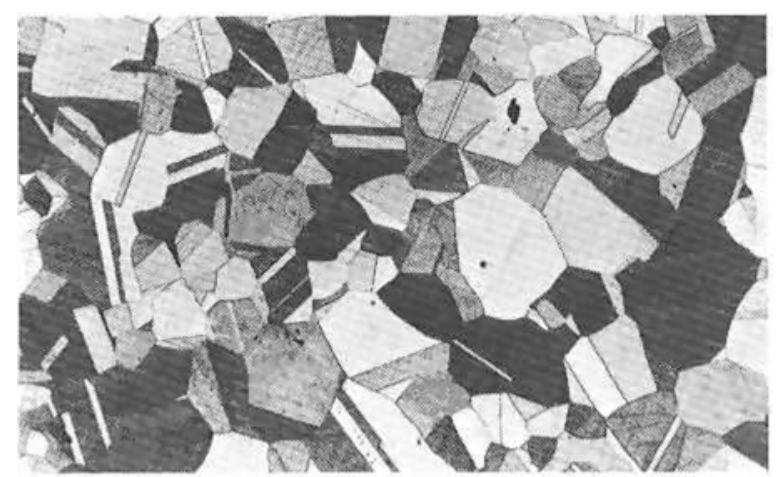

Fig. 418 carat yellow gold, annealed 1 hour, $800^{\circ} \mathrm{C}, \times 100$

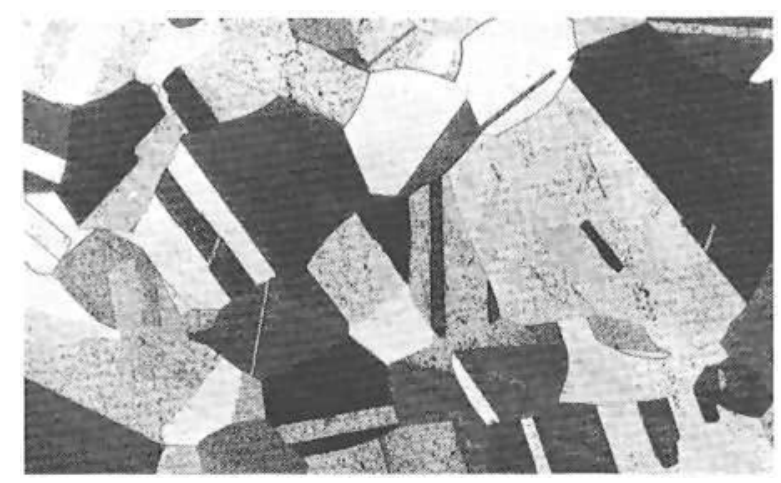

Fig. 618 carat yellow gold $+0.3 \% \mathrm{Cr}$, annealed 1 hour, $800^{\circ} \mathrm{C}, \times 100$

The marked effects of chromium and iron upon grain growth during the annealing of an 18 carat yellow gold (see Table) will be apparent from Figures 1-7 